\title{
Measuring performance of virtual learning environment system in higher education
}

\author{
William Ho, Helen E. Higson, Prasanta K. Dey and Xiaowei Xu \\ Aston Business School, Aston University \\ and \\ Rami Bahsoon \\ University of Birmingham, \\ Birmingham, United Kingdom
}

(The article was originally submitted on the $1^{\text {st }}$ March, and a revised submission was made on the $7^{\text {th }}$ June 2008. A further revision was made on $12^{\text {th }}$ September 2008. The article was finally approved on the $20^{\text {th }}$ September 2008.)

\begin{abstract}
Purpose - Virtual learning environments (VLE) have become a prevalent tool in higher education institutions for supporting and facilitating both teaching and learning. They form a platform for teachers and learners to access lecture notes, read announcements, communicate with others, complete assignments, participate in discussions and group work, and take quizzes and tests. Nowadays, there are plenty of commercial VLE systems available in the market. Each of them possesses its own characteristics and features. The purpose of this paper is to measure the performance of these systems, which helps the decision makers to select the appropriate system for their institutions.
\end{abstract}

Design/methodology/approach - This paper develops an integrated multiple criteria decision making approach, which combines the analytic hierarchy process (AHP) and quality function deployment (QFD), to evaluate and select the best system. The evaluating criteria are derived from the requirements of those who use the system. A case study is provided to demonstrate how the integrated approach works.

Findings - The major advantage of the integrated approach is that the evaluating criteria are of interest to the stakeholders. This ensures that the selected system will achieve the requirements and satisfy the stakeholders most. Another advantage is that the approach can guarantee the benchmarking to be consistent and reliable. From the case study, it is proved 
that the performance of a VLE system being used at the university is the best. Therefore, the university should continue to run the system in order to support and facilitate both teaching and learning.

Originality/value - To the best of our knowledge, there is no study that measures the performance of VLE systems, and thus decision makers may have difficulties in system evaluation and selection for their institutions.

Keywords: Higher education; Virtual learning environment; Performance measurement; Analytic hierarchy process; Quality function deployment. 


\section{Introduction}

A virtual learning environment (VLE) is a software system designed to support teaching and learning. VLEs generally operate on the World Wide Web, and, therefore, they can be accessed both on and off-campus, provided that the users are registered and can access the Internet. This overcomes the limitation of traditional face-to-face teaching, and ensures that learning is neither confined to geographical location nor time. VLEs are becoming more popular and embedded in many higher education institutions around the world. It is not only because of their flexibility, but also because they provide a wide variety of tools or facilities, including content delivery, assessment, evaluation, communications, and so on (Chin, 2004).

There are various commercial VLE products or systems available, such as Blackboard, COSE, Learnwise, and WebCT. Each of them possesses its own characteristics, and is used in different higher education institutions. A question is, therefore, raised "Which VLE system performs the best?" The advantage of selecting an optimal VLE system is to facilitate faculty members in the management of module contents and also enhance the learning experience of students through the assessment, evaluation, and communication tools. Therefore, an evaluation and selection of VLE systems is a crucial strategic decision for a higher education institution.

To assist the VLE system evaluation or answer the above query, this paper develops an integrated multiple criteria decision making approach that combines the analytic hierarchy process (AHP) and quality function deployment (QFD). In the approach, multiple evaluating criteria are derived from the requirements of higher education stakeholders using QFD. The importance of evaluating criteria is prioritized with respect to the degree of achieving the stakeholder requirements using AHP. Based on the ranked criteria, alternative VLE systems are evaluated and compared with each other using AHP again to make an optimal selection.

This paper is organized as follows. Section 2 reviews the relevant literature concerning the applications of individual AHP, individual QFD, and the integrated approach in higher education. Sections 3 and 4 describe the principles of AHP and QFD, respectively. Section 5 presents the computational procedures of the integrated approach for the VLE system selection. Section 6 demonstrates the implementation of the proposed approach in a real case. Section 7 analyzes the results, and investigates how the performance of the selected system can be improved further. Finally, Section 8 concludes the paper. 


\section{2. $\quad$ Related work}

\subsection{Applications of AHP in higher education}

Kwak and Lee (1998) studied the problem of allocating higher education institution's resources to IT-based projects. AHP was used first to evaluate the relative importance weightings of alternative networking methods (one of the IT-based projects) with respect to four criteria: risk, performance, conversion, and development. The weightings were then incorporated into the objective function of the goal programming model. The model was to select the optimal combination of projects according to the limited budget available.

Ozdemir and Gasimov (2004) formulated a binary nonlinear programming model with multiple objectives for the faculty course assignment problem. Due to the complexity of the model, they reduced the multiple objective functions to a single objective function. AHP was used to determine the relative importance weightings of the objectives or the preferences of instructors and administrators. The reduced integer linear programming model was to select the best assignment so that the instructor and administrator satisfaction was maximized.

Badri and Abdulla (2004) proposed a model that identifies relevant and essential criteria in measuring the performance of individual departmental staff for reward purposes. AHP was adopted to prioritize three criteria: research and publication, teaching, and community and university services. The higher score a faculty member gets, the higher possibility that he/she can win awards for excellence.

Kim, Han, Kim and Choi (2005) focused on the curriculum design for e-commerce security. AHP was used to determine the priority rankings of alternative e-commerce security courses with respect to the comments of professionals in universities, research institutes, ebusinesses, and IT companies.

Lee and Lee (2006) investigated the factors affecting the selection of subject specialization by business students. The authors applied AHP to rank the alternative subject streams, including accounting, finance, information systems, management, management science, and marketing, with respect to four criteria: personal, others, institutional, and career preferences.

Ho, Dey and Higson (2007) studied the resource allocation problem in a university. AHP was used first to determine the relative importance of the proposed projects with respect to three university's goals: teaching, quality, and consultancy. The relative importance was then incorporated into the goal programming model. The model was to select the best set of projects that contributes to the university most. Besides budgeting constraints, other resources were considered in the model, such as space and time. 


\subsection{Applications of QFD in higher education}

Jaraiedi and Ritz (1994) applied QFD to improve the quality of engineering education at the West Virginia University in the United States. Based on student expectations from classes that they attend, several design requirements that will fulfill the demands were proposed. The design requirements with higher importance ratings should receive more attention.

Wiklund and Wiklund (1999) used QFD to improve student satisfaction and learning at the Luleå University of Technology in Sweden. By focusing on the student needs, multiple attributes of a graduate course in quality technology were developed. Besides applying QFD to identify which course attributes should be incorporated, the authors carried out two separate conjoint analyses. The first analysis was to study how the project course should actually be performed in order to enhance student satisfaction, whereas the second analysis was to identify the factors that have a positive effect on student individual learning.

Hwarng and Teo (2001) designed and delivered an operations management course at the National University of Singapore with an aid of QFD. Three houses of quality (HOQ) were constructed, including HOQ1 - linking student wants and service elements, HOQ2 linking service elements and key process operations, and HOQ3 - linking key process operations and operations requirements. Besides course design and delivery, the proposed methodology was also applied to student online course registration and to staff research grant application.

Duffuaa, Al-Turki and Hawsawi (2003) applied QFD to design and deliver a basic statistics course at the King Fahd University of Petroleum and Minerals in Saudi Arabia. Instead of simply listening to student voices, requirements of faculty members and organizations from industry were also considered. Several alternative course design concepts that satisfy the requirements were developed.

Sahney, Banwet and Karunes $(2003$; 2004) used QFD to improve the quality of education and student satisfaction at the Indian educational institutions. A single HOQ that links the student requirements and design characteristics was created. The interrelationship between the different design characteristics was determined in order to identify the minimum set of characteristics that can achieve the relatively important student requirements.

Chou (2004) applied QFD to evaluate the quality of undergraduate nursing education in Taiwan. Based on the desires of undergraduate nursing students, various service elements were proposed for their nursing education program. 
Aytaç and Deniz (2005) studied the curriculum design problem for the Tyre Technology Department at the Kocaeli University Köseköy Vocational School of Higher Education in Turkey. The QFD approach proposed was very similar to the above, except the way of assigning the importance ratings of customer requirements. After determining the student expectations, both Turkish tyre companies and department lecturers ranked the expectations according to their perspectives. Based on the student expectations, several quality characteristics of courses were developed.

Denton, Kleist and Surendra (2005) proposed QFD to aid the design of curriculum and course in the academic domain of management information systems. Two conceptual and incomplete HOQs were constructed, including HOQ1 - linking student abilities and knowledge requirements, and $\mathrm{HOQ} 2$ - linking knowledge requirements and course activities.

Thakkar, Deshmukh and Shastree (2006) used a QFD model with four HOQs to improve the quality of education in the self-financed technical institutions. The authors described the first HOQ only, which translated the student requirements into the expected characteristics of technical institutions.

\subsection{Applications of the integrated AHP-QFD approach in higher education}

Köksal and Eğitman (1998) applied the integrated AHP-QFD approach to improve the quality of education for the Department of Industrial Engineering at the Middle East Technical University in Turkey. AHP was adopted to evaluate the importance ratings of stakeholder requirements. The alternative education design requirements were then prioritized based on the AHP ratings together with the relationship weightings between the education requirements and stakeholder requirements.

Lam and Zhao (1998) used the integrated AHP-QFD approach to identify appropriate teaching techniques. AHP was used to evaluate the importance ratings of student requirements with respect to three criteria: skills development, interest and knowledge, and examination and job. Similar to Köksal and Eğitman (1998), the alternative teaching techniques were prioritized based on the AHP ratings and the relationship weightings between student requirements and teaching techniques.

\subsection{Summary}

The applications of AHP, QFD, and their integration are summarised in Table I. The applicability of AHP in higher education is broad. It has been applied to three of the main higher education decision problems (Ho, Higson and Dey, 2006), including resource 
allocation (Kwak and Lee, 1998; Ho et al., 2007), performance measurement (Badri and Abdulla, 2004; Kim et al., 2005; Lee and Lee, 2006), and scheduling (Ozdemir and Gasimov, 2004).

QFD has attracted more attention than AHP in the field of higher education. A common point among the literatures is that all previous researchers used QFD for course and curriculum design problems. Most of them proposed a single HOQ approach (Jaraiedi and Ritz, 1994; Wiklund and Wiklund, 1999; Duffuaa et al., 2003; Sahney et al., 2003; Chou, 2004; Sahney et al., 2004; Aytaç and Deniz, 2005), whereas few of them used multiple HOQs (Hwarng and Teo, 2001; Denton et al., 2005; Thakkar et al., 2006) to improve the quality of education.

In both single and multiple HOQ approaches, the previous researchers used the traditional scaling method to determine the importance ratings of customer requirements and the relationship weightings subjectively. This might result in a certain degree of inconsistency, and, therefore might degrade the quality of decisions made. To overcome this drawback, two groups of researchers (Köksal and Eğitman, 1998; Lam and Zhao, 1998) applied the integrated AHP-QFD approach for the course and curriculum design problem. Nevertheless, AHP was used to determine the importance ratings of customer requirements only, but not the relationship weightings.

According to the above literature, none of the previous researchers have applied AHP or QFD to measure the performance of VLE systems. Lack of appropriate research contribution is the primal motivation of this paper. Besides, AHP is used to determine the relationship weightings of QFD in order to guarantee that the decision made is consistent and satisfactory.

\section{'Take in Table I here'}

\section{Analytic hierarchy process}

AHP, developed by Saaty (1980), comprises three main operations, including hierarchy construction, priority analysis, and consistency verification. First, the decision makers need to break down complex multiple criteria decision problems into its component parts, of which all possible attributes are arranged into multiple hierarchical levels. The goal, criteria, and alternatives of each criterion are in the first, second, and third levels, respectively.

Second, the decision makers have to compare each cluster in the same level in a pairwise fashion based on their own experience and knowledge. Every two criteria in the 
second level are compared at each time with respect to the goal while every two alternatives in the third level are compared at a time with respect to their corresponding criteria. A judgment is made about which is more important and by how much. Subjective judgment can be depicted using quantitative scales which are usually divided into 9-point scale, shown in Table II, to enhance the transparency of decision making process. Based on the pairwise matrix, the priority of each element in terms of its contribution to the overall goal can be calculated. This process is referred to as synthesization.

'Take in Table II here'

Because the comparisons are carried out through personal or subjective judgments, some degree of inconsistency may occur. To guarantee that the judgments are consistent, the final operation called consistency verification, which is regarded as one of the greatest advantages of AHP, is incorporated to measure the degree of consistency among the pairwise comparisons by computing the consistency ratio. If it is found that the ratio exceeds the limit (0.10), the decision makers should review and revise the pairwise comparisons.

\section{Quality function deployment}

QFD is a structured product (or service) development approach. It is so-called because it emphasizes understanding and achieving customer requirements. In addition, this approach uses interfunctional team from marketing, design engineering, and manufacturing for developing the product or service. One of the tools of QFD is the HOQ, which is a matrix for relating the customer requirements with the product (Heizer and Render, 2006).

There are several steps in constructing a generic HOQ. First of all, the interfunctional QFD team develops a list of customer requirements for the product. These requirements are then ranked in order of importance according to the customer perspectives. The third step is to identify specific product characteristics, features, or attributes that will satisfy the customer requirements. After that, the team relates customer requirements to product attributes, that is, determining the relationship weightings. Next, the team determines the relationships among the product attributes. This step aims at finding any conflicting product attributes, and then making a trade-off decision to overcome the conflicts. Based on the importance ratings of customer requirements and the relationship weightings, the importance ratings of the product attributes are computed. This step aims at determining the order of importance for the product attributes, and deciding which set of attributes should be given priority in product 
development. Following that, the performance of competing products is evaluated with respect to the customer requirements. Finally, the team determines the optimal settings for the product attributes, and compares the company performance with the competitor performance with respect to the optimal attribute settings.

The HOQ approach may involve a sequence of houses. For example, in the product development process, it may start with design characteristics, then leads to specific components, production process, and finally quality plan. The quality plan comprises a variety of decisions, including methods, procedures, sampling techniques, and tolerances that will ensure that the production process meets the customer requirements.

\section{Proposed methodology}

The proposed methodology, integrating AHP and QFD, for benchmarking VLE system alternatives is described in the following steps. As illustrated in Figure 1, the approach comprises a series of three houses, including HOQ1 (refer to steps 1 to 5), HOQ2 (refer to steps 6 to 9), and HOQ3 (refer to steps 10 to 13).

\section{'Take in Figure 1 here'}

Step 1: Identify the HE stakeholders who use the VLE system.

Step 2: Determine the proportion of each stakeholder category.

Step 3: Identify the stakeholder requirements.

Step 4: Determine the relationship weightings between the HE stakeholders and stakeholder requirements using AHP (steps 4.1 to 4.7).

Step 4.1: $\quad$ AHP pairwise comparison

Construct a pairwise comparison matrix,

$$
A=\left[\begin{array}{cccc}
a_{11} & a_{12} & \cdots & a_{1 n} \\
a_{21} & a_{22} & \cdots & a_{2 n} \\
\vdots & \vdots & \ddots & \vdots \\
a_{n 1} & a_{n 2} & \cdots & a_{n n}
\end{array}\right],
$$

where $n$ denotes the number of elements (stakeholder requirements in HOQ1), and $a_{i j}$ refers to the comparison of element $i$ to element $j$ with respect to each criterion (HE stakeholders in HOQ1). The 9-point scale, shown in Table II, can be used to decide on which element is more important and by how much.

Step 4.2: $\quad$ AHP synthesization 
Divide each entry $\left(a_{i j}\right)$ in each column of matrix $A$ by its column total. The matrix now becomes a normalized pairwise comparison matrix,

$$
A^{\prime}=\left[\begin{array}{cccc}
\frac{a_{11}}{\sum_{i \in R} a_{i 1}} & \frac{a_{12}}{\sum_{i \in R} a_{i 2}} & \cdots & \frac{a_{1 n}}{\sum_{21} a_{i n}} \\
\frac{a_{21}}{\sum_{i \in R} a_{i 1}} & \frac{a_{22}}{\sum_{i \in R} a_{i 2}} & \cdots & \frac{a_{2 n}}{\sum a_{i n}} \\
\vdots & \vdots & \ddots & \vdots \\
\frac{a_{n 1}}{\sum_{i \in R} a_{i 1}} & \frac{a_{n 2}}{\sum_{i \in R} a_{i 2}} & \cdots & \frac{a_{n n}}{\sum a_{i n}}
\end{array}\right],
$$

where $R$ denotes the set of stakeholder requirements, that is, $R=\{1,2, \ldots, n\}$.

Step 4.3: Compute the average of the entries in each row of matrix $A^{\prime}$ to yield column vector,

$$
C=\left[\begin{array}{c}
c_{1 k}^{1} \\
\vdots \\
c_{n k}^{1}
\end{array}\right]=\left[\begin{array}{c}
\frac{\left(\frac{a_{11}}{\sum_{i \in R} a_{i 1}}+\frac{a_{12}}{\sum_{i \in R} a_{i 2}}+\cdots+\frac{a_{1 n}}{\sum_{i \in R} a_{i n}}\right)}{n} \\
\vdots \\
\left.\frac{a_{n 1}}{\sum_{i \in R} a_{i 1}}+\frac{a_{n 2}}{\sum_{i \in R} a_{i 2}}+\cdots+\frac{a_{n n}}{\sum_{i \in R} a_{i n}}\right) \\
n
\end{array}\right],
$$

where $c_{i k}^{1}$ denotes the relationship weightings between stakeholder requirement $i$ and its corresponding stakeholder $k$ in HOQ1.

\section{Step 4.4: $\quad$ AHP consistency verification}

Multiply each entry in column $i$ of matrix $A$ by $c_{i k}^{1}$. Then, divide the summation of values in row $i$ by $c_{i k}^{1}$ to yield another column vector,

$$
\bar{C}=\left[\begin{array}{c}
\bar{c}_{1 k}^{1} \\
\vdots \\
\bar{c}_{n k}^{1}
\end{array}\right]=\left[\begin{array}{c}
\frac{c_{1 k}^{1} a_{11}+c_{2 k}^{1} a_{12}+\cdots c_{n k}^{1} a_{1 n}}{c_{1 k}^{1}} \\
\vdots \\
\frac{c_{1 k}^{1} a_{n 1}+c_{2 k}^{1} a_{n 2}+\cdots c_{n k}^{1} a_{n n}}{c_{n k}^{1}}
\end{array}\right],
$$

where $\bar{C}$ refers to a weighted sum vector.

Step 4.5: Compute the averages of values in vector $\bar{C}$ to yield the maximum eigenvalue of matrix $A$, 
$\lambda_{\max }=\frac{\sum_{i \in R} \bar{c}_{i k}^{1}}{n}$.

Step 4.6: Compute the consistency index,

$C I=\frac{\lambda_{\max }-n}{n-1}$.

Step 4.7: Compute the consistency ratio,

$C R=\frac{C I}{R I(n)}$,

where $R I(n)$ is a random index the value of which is dependent on the value of $n$, shown in Table III. If $C R$ is greater than 0.10, then go to step 4.1. Otherwise, go to step 5 .

Step 5: Compute the importance rating of each stakeholder requirement,

$w_{i}^{1}=\sum_{k \in S} p_{k} c_{i k}^{1}$

where $S$ denotes the set of HE stakeholders, that is, $S=\{1,2, \ldots, m\}$, and $p_{k}$ denotes the proportion of stakeholder $k$.

Step 6: Copy the stakeholder requirements (step 3) and their corresponding importance ratings (step 5) into HOQ2.

Step 7: Identify the VLE system features.

Step 8: Determine the relationship weightings between VLE system features $i$ and its corresponding stakeholder requirements $k, c_{i k}^{2}$, using AHP (steps 4.1 to 4.7). Note that, in HOQ2, $R$ denotes the set of VLE system features, that is, $R=\{1,2, \ldots$, $n\}$, whereas $S$ denotes the set of stakeholder requirements, that is, $S=\{1,2, \ldots$, $m\}$.

Step 9: Compute the importance rating of each VLE system feature, $w_{i}^{2}=\sum_{k \in S} \bar{w}_{k}^{1} c_{i k}^{2}$,

where $\bar{w}_{k}^{1}$ is computed in step 5 .

Step 10: Copy the VLE system features (step 7) and their corresponding importance ratings (step 9) into HOQ3.

Step 11: Identify the VLE system alternatives.

Step 12: Determine the relationship weightings between VLE systems $i$ and its corresponding VLE system features $k, c_{i k}^{3}$, using AHP (steps 4.1 to 4.7). Note 
that, in HOQ3, $R$ denotes the set of VLE system alternatives, that is, $R=\{1,2$, $\ldots, n\}$, whereas $S$ denotes the set of VLE system features, that is, $S=\{1,2, \ldots$, $m\}$.

Step 13: Finally, calculate the total score of each alternative VLE system,

$$
w_{i}^{3}=\sum_{k \in S} \bar{w}_{k}^{2} c_{i k}^{3}
$$

where $\bar{w}_{k}^{2}$ is computed in step 9.

\section{'Take in Table III here'}

\section{A case study}

A university, which has four schools, is running two different VLE systems for supporting teaching and learning. Each of them is dedicated to two schools. System A is used by the School of Engineering and School of Life and Health Sciences, whereas System B is used by the School of Business and School of Languages and Social Sciences. Both VLE systems are web-based e-learning platforms which full-time, part-time and distance learners can access course materials on or off-campus anytime and any place. With the VLE systems, staff and students can do a range of useful activities that facilitate their teaching and learning, such as access lecture notes, read announcements, communicate with others, complete assignments, participate in discussions and group work, and take quizzes and tests. Currently, the university is planning to review the performance of VLE systems, including those being used and two other candidate VLE systems (system C and system D). The aim of this review is to determine which VLE is the best in terms of the ability of enhancing both staff and students experience of teaching and learning.

To evaluate and select the best VLE system, the higher education stakeholders who use the VLE systems are identified first. In this case, there are four categories: administrative staff, faculty members, postgraduates, and undergraduates. Then, the proportion of each stakeholder category is determined. In the third step, the stakeholder requirements are identified. According to the results of questionnaire, there are nine requirements of which the descriptions are shown in Table IV. To calculate the importance of stakeholder requirements, the relationship weightings between the stakeholders and their requirements are determined using AHP. For example, the procedure of calculating the relationship weightings for administrative staff is to construct a pairwise comparison matrix first as shown in Figure 2. Because all requirements are related to the administrative staff, there are nine elements in 
matrix $A$. For synthesization, a normalized comparison matrix is constructed as shown in Figure 3. Based on matrix $A^{\prime}$, a column vector showing the relationship weightings between stakeholder requirements and administrative staff is constructed as shown in Figure 4. To verify the consistency, a weighted sum vector is constructed as shown in Figure 5. Then, the maximum eigenvalue of matrix $A$, consistency index, and consistency ratio are computed as follows.

'Take in Table IV here'

'Take in Figures 2 to 5 here'

$$
\begin{gathered}
\lambda_{\max }=\frac{9.128+9.194+9.617+9.077+9.424+9.237+9.251+9.596+9.638}{9}=9.351 \\
C I=\frac{9.351-9}{9-1}=0.044 \\
C R=\frac{0.044}{1.45}=0.030
\end{gathered}
$$

Because $C R$ is less than 0.10 , the pairwise comparison for the administrative staff is consistent. Following the above procedure for determining the relationship weightings between the stakeholder requirements and the remaining three stakeholders, the importance ratings of each stakeholder requirement can be computed in HOQ1 as shown in Figure 6. Note that there are eight elements in the pairwise comparison matrices for the faculty members, postgraduates, and undergraduates. It is because the ninth requirement "provide after-sale service" is not of interest to them. According to HOQ1, "get started easily" is the most important requirement, whereas "provide after-sale services" is the least important.

\section{'Take in Figure 6 here'}

After completing HOQ1, both stakeholder requirements and their corresponding importance ratings are copied into HOQ2, which links the requirements and VLE system features. In this case, there are 28 features that the VLE system should possess in order to achieve the stakeholder requirements. Table V shows the descriptions of system features. Similar to HOQ1, AHP is used to calculate the relationship weightings between the stakeholder requirements and VLE system features in HOQ2. Certainly, the size of each pairwise comparison matrix is varied, and is dependent on the number of system features that 
will achieve a particular requirement. For example, there are four elements in the matrix for the requirement "upload/download documents and course work efficiently". They are "system speed", "multiple file uploads", "digital dropbox", and "continuous product evolution". All these four system features or elements are relevant to the requirement. After determining all relationship weightings between the nine stakeholder requirements and their related system features, the importance ratings of each feature can be computed in HOQ2 as shown in Figures 7 and 8. According to HOQ2, "user-friendly" is the most important feature, whereas "ease of maintenance" is the least important.

\section{'Take in Table V here'}

'Take in Figures 7 and 8 here'

In the last stage, both system features and their corresponding importance ratings are copied into HOQ3, which evaluates the VLE systems with respect to the 28 system features. As mentioned earlier, there are four system alternatives to be evaluated, including two being used at the university and two other candidate systems. AHP is used again to calculate the relationship weightings between the VLE system features and system alternatives in HOQ3. There are 28 pairwise comparison matrices constructed in which the size of each matrix is not always equal to four. Its size is dependent on the number of systems that possesses the equivalent feature. After determining all relationship weightings, the importance ratings of each alternative system can be computed in HOQ3 as shown in Figure 9. Note that the summation of total scores is not equal to one (0.907). It is because all the systems can neither link with the Webmail portal (0.060) nor inform users of receiving new emails (0.034). According to HOQ3, the performance of system B is the best, followed by systems A, C, and D. Therefore, the university should continue to run system B for the School of Business and School of Languages and Social Sciences, and also replace system A by system B for the School of Engineering and School of Life and Health Sciences.

'Take in Figure 9 here'

\section{Result analysis}

In this section, we focus on comparing alternative VLE systems with respect to the six most important requirements. These requirements are dominant because their total importance ratings are 0.916 . The attributes of each requirement will be analyzed to 
understand why system B outperforms the others, and how its performance can be improved further.

First of all, the most important requirement is to "get started easily", in which there are four attributes as shown in Table VI. System B gets the highest score mainly because it is the most user-friendly platform. Unlike system A, it does not require any programming skills. In addition, it is easy to navigate and provides a comprehensive and integrated help support for the users, including user manual, tutorial guide, and multi-language support.

'Take in Table VI here'

The comparison of alternative systems with respect to the second most important requirement (i.e., "find and locate documents and course information easily") is shown in Table VII. System B should pay more attention to the improvement of its search engine. In the current version, it can only be used to search for the modules by module names or codes. To facilitate users in finding the documents and course information easily, the search engine should be able to search for a particular document and file and also be incorporated with basic, advanced, or even expert search selection. Besides, system B should provide a direct link to the student record system as is the case with system A. This enables the students to find out the course and personal information, including module scheduling, examination scheduling, student placements, and so on. To increase its stakeholder satisfaction further, system B should obviously be able to inform stakeholders of new documents. For example, a popup window is shown if there are new documents and announcements. Moreover, different hyperlink style is used to differentiate between read and unread documents. A book function should also be incorporated in system B to allow users to find their favorite and frequently visited locations easily.

'Take in Table VII here'

The comparison of alternative systems with respect to the third most important requirement (i.e., "upload/download documents and course work efficiently") is shown in Table VIII. System B performs better than the other three systems except that a single file can only be uploaded to the system at a time. This will certainly decrease the efficiency of administrative staff and faculty members in cases where they have plenty of files to post. 
The fourth most important requirement is "communicate and collaborate with others", in which there are eight attributes as shown in Table IX. Among them, system B scores the highest in five attributes. To improve its performance further, system B should focus on the remaining three attributes. First, the current version of system B can only be used to write and send (but not read) emails. Besides, emails can merely be sent to a specific group of stakeholders. To overcome this drawback, it should provide a direct link with the university Webmail portal so that the stakeholders can communicate and collaborate with others easily. Second, system B should provide an instant messaging feature in the discussion board or forum. This enables a real-time communication between the stakeholders, and fosters knowledge sharing and transferring among the stakeholders. Third, system B should allow students to check the availability of module leaders and also make appointments for consultation.

'Take in Table IX here'

The comparison of alternative systems with respect to the fifth most important requirement (i.e., "provide emailing support") is shown in Table X. Besides linking with the university Webmail portal directly, system B should also be able to inform the stakeholders of new emails as the case with Microsoft Outlook Express.

\section{'Take in Table X here'}

Finally, the comparison of alternative systems with respect to the sixth most important requirement (i.e., "search for reference materials") is shown in Table XI. The performance of system B is worse than that of system A in three aspects. First, its search engine is not as robust as that of system A, as discussed earlier. Second, system B should provide a direct link with the library information system portal. This enables the students to search for reference materials directly and easily even if the module leaders have not provided a hyperlink to the portal. Third, it should have a book function to allow users to find their favorite and frequently visited locations easily. 
Note that systems $\mathrm{C}$ and $\mathrm{D}$ have not been mentioned in the above analyses. It is because their performance is worse than systems $\mathrm{A}$ and B. Therefore, the university should not consider either system $\mathrm{C}$ or system $\mathrm{D}$ unless they have made significant improvement in the system features that will satisfy the requirements of its stakeholders.

\section{Conclusions}

This paper developed an integrated multiple criteria decision making approach to measure the performance of alternative VLE systems. A case study was given to demonstrate how it works. In the approach, QFD was used to translate the higher education stakeholder requirements into multiple system features, which were also regarded as the evaluating criteria for benchmarking the systems. AHP was used to determine the relationship weightings consistently. The major advantage of this integrated approach is that the evaluating criteria are of interest to the stakeholders. This ensures that the selected system will achieve the requirements and satisfy the stakeholders most. Another advantage is that the approach can guarantee the benchmarking to be consistent and reliable. Besides selecting the best system for the university, in-depth analyses were carried out to examine the strengths of the selected system and also the way of eliminating its weaknesses so that its performance can be improved further.

There are three potential beneficiaries of this project, including decision makers of higher education institutions, higher education stakeholders, and VLE system developers. First of all, the proposed approach can support the decision makers of universities in reviewing their existing VLE systems and determining whether it is necessary to replace the existing systems by a better one. Besides, the proposed approach can support the decision makers of universities, who are planning to set up a VLE system, in evaluating and selecting the best system. Certainly, the selection and adoption of an appropriate VLE system in a university is beneficial to its stakeholders in terms of teaching and learning. Finally, the proposed approach can support the VLE system developers in analyzing their strengths and weaknesses, and also identifying the opportunities and threats against the competing systems. 


\section{Glossary}

AHP - Analytic hierarchy process

$\mathrm{CR}$ - Consistency ratio

HOQ - House of quality

QFD - Quality function deployment

VLE -Virtual learning environments

\section{Acknowledgements}

The work described in this paper was supported by a HELM small research grant, from Aston University. The authors would also like to acknowledge Mr. David Anderson for providing information on alternative VLE systems.

\section{Reference}

Aytaç, A., Deniz, V., 2005. Quality function deployment in education: a curriculum review. Quality \& Quantity 39, 507-514.

Badri, M.A., Abdulla, M.H., 2004. Awards of excellence in institutions of higher education: an AHP approach. International Journal of Educational Management 18 (4), 224-242.

Chin, P., 2004. Using C\&IT to Support Teaching. RoutledgeFalmer, London.

Chou, S.M., 2004. Evaluating the service quality of undergraduate nursing education in Taiwan - using quality function deployment. Nurse Education Today 24, 310-318.

Denton, J.W., Kleist, V.F., Surendra, N., 2005. Curriculum and course design: a new approach using quality function deployment. Journal of Education for Business 81 (2), $111-117$.

Duffuaa, S.O., Al-Turki, U.M., Hawsawi, F.M., 2003. Quality function deployment for designing a basic statistics course. International Journal of Quality \& Reliability Management 20 (6), 740-750.

Ho, W., Higson, H.E., Dey, P.K., 2006. Multiple criteria decision-making techniques in higher education. International Journal of Educational Management 20 (5), 319-337.

Ho, W., Dey, P.K., Higson, H.E., 2007. An integrated multiple criteria decision making approach for resource allocation in higher education. International Journal of Innovation and Learning 4 (5), 471-486.

Heizer, J., Render, B., 2006. Operations Management. Prentice Hall, New Jersey. 
Hwarng, H.B., Teo, C., 2001. Translating customers' voices into operations requirements: a QFD application in higher education. International Journal of Quality \& Reliability Management 18 (2), 195-225.

Jaraiedi, M., Ritz, D., 1994. Total quality management applied to engineering education. Quality Assurance in Education 2 (1), 32-40.

Kim, H., Han, Y., Kim, S., Choi, M., 2005. A curriculum design for e-commerce security. Journal of Information Systems Education 16 (1), 55-64.

Köksal, G., Eğitman, A., 1998. Planning and design of industrial engineering education quality. Computers \& Industrial Engineering 35 (3-4), 639-642.

Kwak, N.K., Lee, C.W., 1998. A multicriteria decision-making approach to university resource allocations and information infrastructure planning. European Journal of Operational Research 110 (2), 234-242.

Lam, K., Zhao, X., 1998. An application of quality function deployment to improve the quality of teaching. International Journal of Quality \& Reliability Management 15 (4), 389-413.

Lee, Y., Lee, S.J., 2006. The competitiveness of the information systems major: an analytic hierarchy process. Journal of Information Systems Education 17 (2), 211-221.

Ozdemir, M.S., Gasimov, R.N., 2004. The analytic hierarchy process and multiobjective 0-1 faculty course assignment. European Journal of Operational Research 157 (2), 398408.

Saaty, T.L., 1980. The Analytic Hierarchy Process. McGraw-Hill, New York.

Sahney, S., Banwet, D.K., Karunes, S., 2003. Enhancing quality in education: application of quality function deployment - an industry perspective. Work Study 52 (6), 297-309.

Sahney, S., Banwet, D.K., Karunes, S., 2004. A SERVQUAL and QFD approach to total quality education: a student perspective. International Journal of Productivity and Performance Management 53 (2), 143-166.

Thakkar, J., Deshmukh, S.G., Shastree, A., 2006. Total quality management (TQM) in selffinanced technical institutions: a quality function deployment (QFD) and force field analysis approach. Quality Assurance in Education 14 (1), 54-74.

Wiklund, P.S., Wiklund, H., 1999. Student focused design and improvement of university courses. Managing Service Quality 9 (6), 434-443.

Contact person: Dr William Ho; email: w.ho@aston.ac.uk 


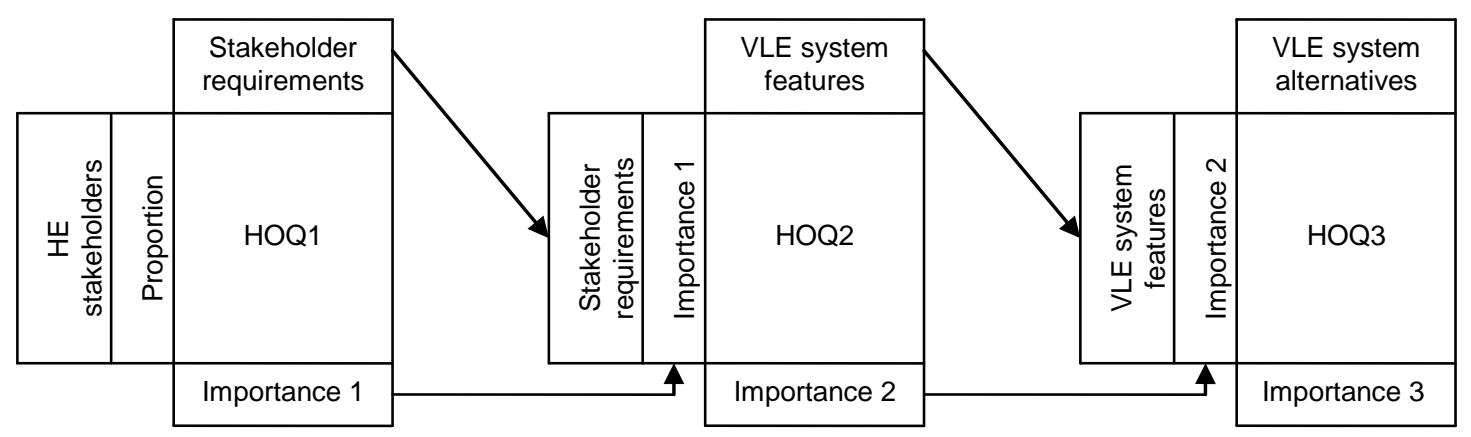

Figure 1. Proposed methodology for VLE system benchmarking

$$
A=\left[\begin{array}{ccccccccc}
1 & \frac{1}{2} & \frac{1}{5} & 2 & \frac{1}{3} & 3 & \frac{1}{2} & \frac{1}{7} & \frac{1}{6} \\
2 & 1 & \frac{1}{4} & 3 & \frac{1}{2} & 4 & \frac{1}{2} & \frac{1}{6} & \frac{1}{5} \\
5 & 4 & 1 & 6 & 2 & 6 & 3 & \frac{1}{3} & \frac{1}{2} \\
\frac{1}{2} & \frac{1}{3} & \frac{1}{6} & 1 & \frac{1}{5} & 2 & \frac{1}{4} & \frac{1}{8} & \frac{1}{7} \\
3 & 2 & \frac{1}{2} & 5 & 1 & 5 & 2 & \frac{1}{4} & \frac{1}{3} \\
\frac{1}{3} & \frac{1}{4} & \frac{1}{6} & \frac{1}{2} & \frac{1}{5} & 1 & \frac{1}{5} & \frac{1}{9} & \frac{1}{8} \\
2 & 2 & \frac{1}{3} & 4 & \frac{1}{2} & 5 & 1 & \frac{1}{4} & \frac{1}{3} \\
7 & 6 & 3 & 8 & 4 & 9 & 4 & 1 & 2 \\
6 & 5 & 2 & 7 & 3 & 8 & 3 & \frac{1}{2} & 1
\end{array}\right]
$$

Figure 2. Pairwise comparison matrix 


$$
A^{\prime}=\left[\begin{array}{lllllllll}
0.037 & 0.024 & 0.026 & 0.055 & 0.028 & 0.070 & 0.035 & 0.050 & 0.035 \\
0.075 & 0.047 & 0.033 & 0.082 & 0.043 & 0.093 & 0.035 & 0.058 & 0.042 \\
0.186 & 0.190 & 0.131 & 0.164 & 0.170 & 0.140 & 0.208 & 0.116 & 0.104 \\
0.019 & 0.016 & 0.022 & 0.027 & 0.017 & 0.047 & 0.017 & 0.043 & 0.030 \\
0.112 & 0.095 & 0.066 & 0.137 & 0.085 & 0.116 & 0.138 & 0.087 & 0.069 \\
0.012 & 0.012 & 0.022 & 0.014 & 0.017 & 0.023 & 0.014 & 0.039 & 0.026 \\
0.075 & 0.095 & 0.044 & 0.110 & 0.043 & 0.116 & 0.069 & 0.087 & 0.069 \\
0.261 & 0.285 & 0.394 & 0.219 & 0.341 & 0.209 & 0.277 & 0.347 & 0.417 \\
0.224 & 0.237 & 0.263 & 0.192 & 0.256 & 0.186 & 0.208 & 0.174 & 0.208
\end{array}\right]
$$

Figure 3. Normalized pairwise comparison matrix

$$
C=\left[\begin{array}{l}
0.040 \\
0.056 \\
0.157 \\
0.026 \\
0.101 \\
0.020 \\
0.079 \\
0.305 \\
0.216
\end{array}\right]
$$

Figure 4. Column vector

$$
\bar{C}=\left[\begin{array}{l}
9.128 \\
9.194 \\
9.617 \\
9.077 \\
9.424 \\
9.237 \\
9.251 \\
9.596 \\
9.638
\end{array}\right]
$$

Figure 5. Weighted sum vector 


\begin{tabular}{|c|c|c|c|c|c|c|c|c|c|c|}
\hline \multirow[b]{2}{*}{ HE stakeholders } & \multirow[b]{2}{*}{ 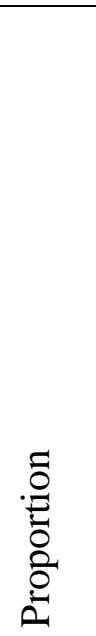 } & \multicolumn{9}{|c|}{ Stakeholder requirements } \\
\hline & & 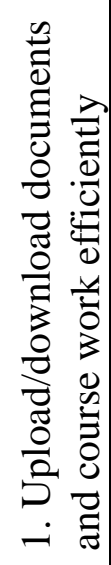 & 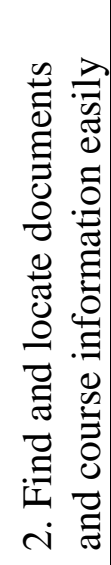 & 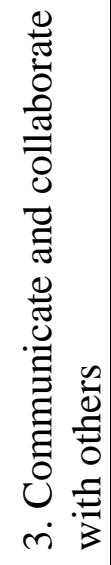 & 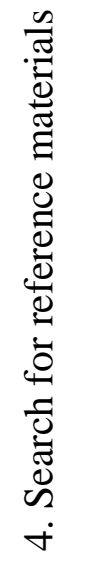 & 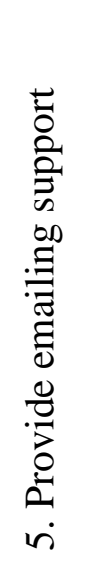 & 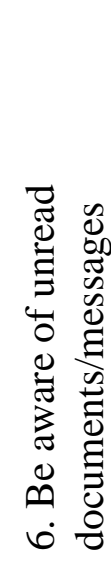 & 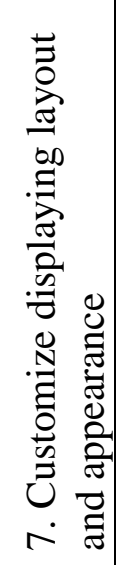 & 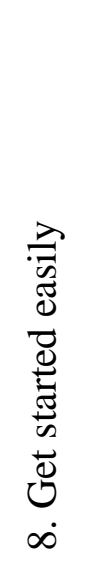 & 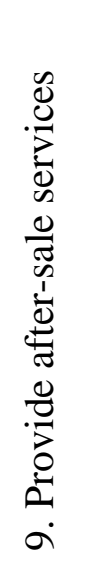 \\
\hline 1. Administrative staff & 0.025 & 0.040 & 0.056 & 0.157 & 0.026 & 0.101 & 0.020 & 0.079 & 0.305 & 0.216 \\
\hline 2. Faculty members & 0.039 & 0.141 & 0.229 & 0.112 & 0.037 & 0.049 & 0.020 & 0.100 & 0.312 & \\
\hline 3. Postgraduates & 0.206 & 0.169 & 0.207 & 0.105 & 0.068 & 0.087 & 0.039 & 0.023 & 0.301 & \\
\hline 4. Undergraduates & 0.730 & 0.142 & 0.254 & 0.093 & 0.040 & 0.083 & 0.057 & 0.024 & 0.308 & \\
\hline $\begin{array}{l}\text { Importance ratings of } \\
\text { stakeholder requirements }\end{array}$ & & 0.145 & 0.238 & 0.098 & 0.045 & 0.083 & 0.051 & 0.028 & 0.307 & 0.005 \\
\hline Ranking & & $3 \mathrm{rd}$ & 2nd & 4th & 6th & 5 th & 7th & 8 th & $1 \mathrm{st}$ & 9th \\
\hline
\end{tabular}

Figure 6. HOQ1 - linking HE stakeholders and their requirements 


\begin{tabular}{|c|c|c|c|c|c|c|c|c|c|c|c|c|c|c|c|}
\hline \multirow[b]{2}{*}{ Stakeholder requirements } & \multirow[b]{2}{*}{ 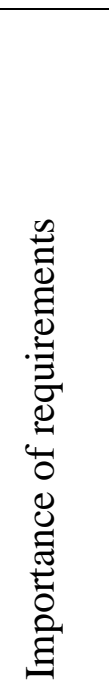 } & \multicolumn{14}{|c|}{ VLE system features } \\
\hline & & 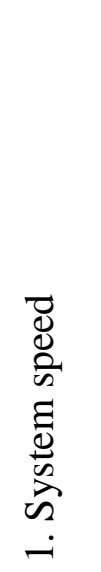 & 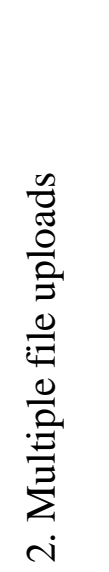 & 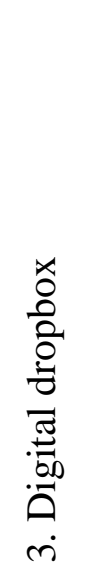 & 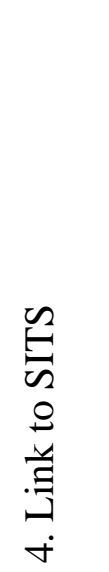 & 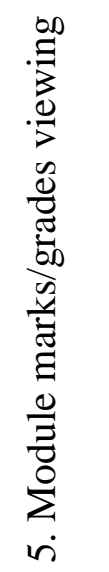 & 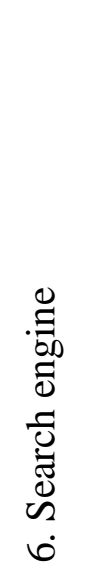 & 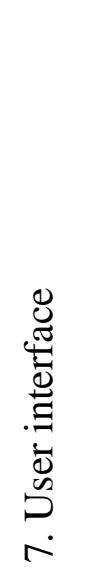 & 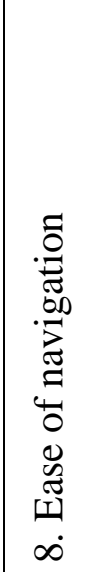 & 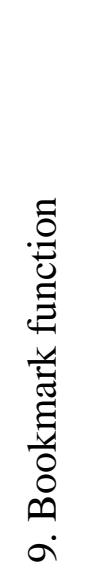 & 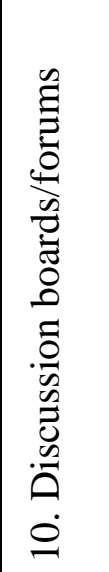 & 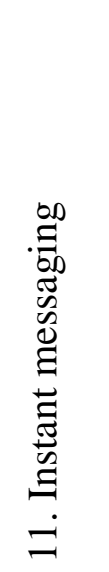 & 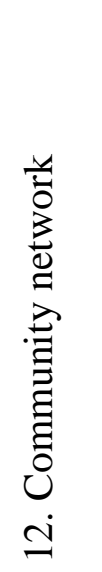 & 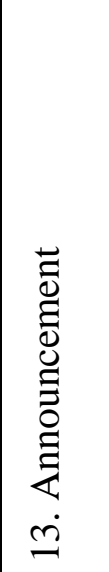 & 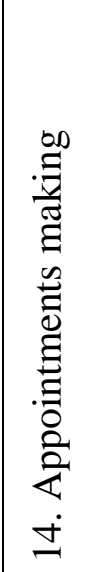 \\
\hline $\begin{array}{l}\text { 1. Upload/download } \\
\text { documents and course work } \\
\text { efficiently }\end{array}$ & 0.145 & 0.456 & 0.146 & 0.303 & & & & & & & & & & & \\
\hline $\begin{array}{l}\text { 2. Find and locate documents } \\
\text { and course information easily }\end{array}$ & 0.238 & & & & 0.117 & 0.117 & 0.271 & 0.030 & 0.215 & 0.022 & & & & & \\
\hline $\begin{array}{l}\text { 3. Communicate and } \\
\text { collaborate with others }\end{array}$ & 0.098 & & & 0.133 & & & & & & & 0.275 & 0.071 & 0.049 & 0.256 & 0.031 \\
\hline $\begin{array}{l}\text { 4. Search for reference } \\
\text { materials }\end{array}$ & 0.045 & & & & & & 0.138 & & & 0.075 & & & & & \\
\hline 5. Provide emailing support & 0.083 & & & & & & & & & & & & & & \\
\hline $\begin{array}{l}\text { 6. Be aware of unread } \\
\text { documents/messages }\end{array}$ & 0.051 & & & & & & & & & & & & & 0.156 & \\
\hline $\begin{array}{l}\text { 7. Customize displaying } \\
\text { layout and appearance }\end{array}$ & 0.028 & & & & & & & 0.143 & & & & & & & \\
\hline 8. Get started easily & 0.307 & & & & & & & & 0.092 & & & & & & \\
\hline 9. Provide after-sale services & 0.005 & & & & & & & & & & & & & & \\
\hline $\begin{array}{l}\text { Importance ratings of VLE } \\
\text { system features }\end{array}$ & & 0.066 & 0.021 & 0.057 & 0.028 & 0.028 & 0.071 & 0.011 & 0.079 & 0.009 & 0.027 & 0.007 & 0.005 & 0.033 & 0.003 \\
\hline Ranking & & 5th & 18th & 7th & 13th & 13th & 4th & $22 \mathrm{nd}$ & 3 rd & $23 r d$ & 15th & 25th & 26th & 12th & 27 th \\
\hline
\end{tabular}

Figure 7. HOQ2 - linking HE stakeholder requirements and VLE system features 


\begin{tabular}{|c|c|c|c|c|c|c|c|c|c|c|c|c|c|c|c|}
\hline \multirow[b]{2}{*}{ Stakeholder requirements } & \multirow[b]{2}{*}{ 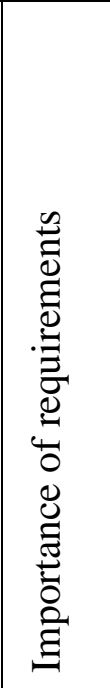 } & \multicolumn{14}{|c|}{ VLE system features } \\
\hline & & 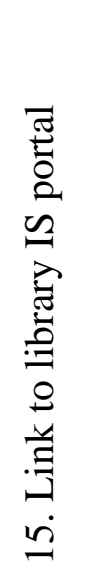 & 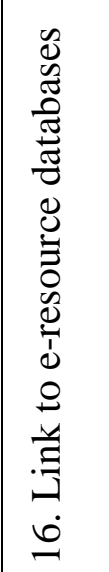 & 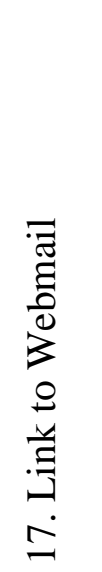 & 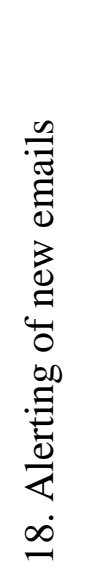 & 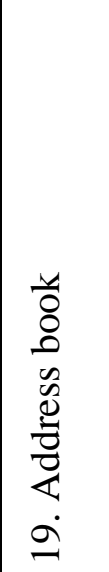 & 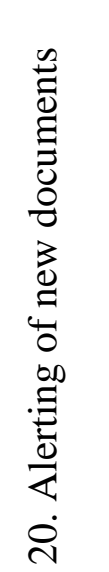 & 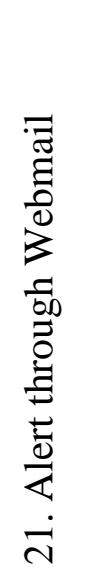 & 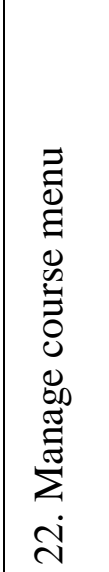 & 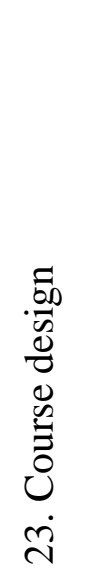 & 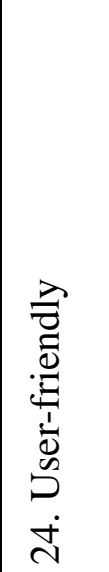 & 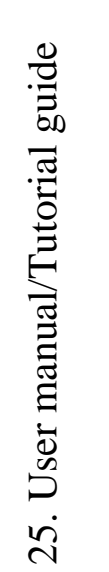 & 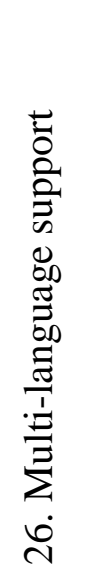 & 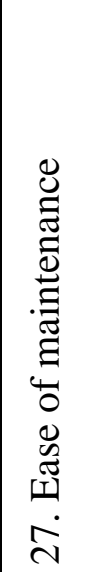 & 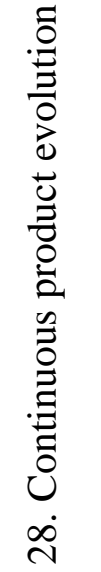 \\
\hline $\begin{array}{l}\text { 1. Upload/download } \\
\text { documents and course work } \\
\text { efficiently }\end{array}$ & 0.145 & & & & & & & & & & & & & & 0.094 \\
\hline $\begin{array}{l}\text { 2. Find and locate documents } \\
\text { and course information easily }\end{array}$ & 0.238 & 0.110 & 0.075 & & & & 0.044 & & & & & & & & \\
\hline $\begin{array}{l}\text { 3. Communicate and } \\
\text { collaborate with others }\end{array}$ & 0.098 & & & 0.162 & & 0.022 & & & & & & & & & \\
\hline $\begin{array}{l}\text { 4. Search for reference } \\
\text { materials }\end{array}$ & 0.045 & 0.394 & 0.394 & & & & & & & & & & & & \\
\hline 5. Provide emailing support & 0.083 & & & 0.483 & 0.229 & 0.080 & & 0.208 & & & & & & & \\
\hline $\begin{array}{l}\text { 6. Be aware of unread } \\
\text { documents/messages }\end{array}$ & 0.051 & & & 0.076 & 0.287 & & 0.330 & 0.151 & & & & & & & \\
\hline $\begin{array}{l}\text { 7. Customize displaying } \\
\text { layout and appearance }\end{array}$ & 0.028 & & & & & & & & 0.429 & 0.429 & & & & & \\
\hline 8. Get started easily & 0.307 & & & & & & & & & & 0.515 & 0.262 & 0.131 & & \\
\hline 9. Provide after-sale services & 0.005 & & & & & & & & & & & 0.179 & 0.083 & 0.410 & 0.328 \\
\hline $\begin{array}{l}\text { Importance ratings of VLE } \\
\text { system features }\end{array}$ & & 0.044 & 0.036 & 0.060 & 0.034 & 0.009 & 0.027 & 0.025 & 0.012 & 0.012 & 0.158 & 0.081 & 0.041 & 0.002 & 0.015 \\
\hline Ranking & & 8th & 10th & 6th & 11th & $23 \mathrm{rd}$ & 15 th & 17th & 20th & 20th & $1 \mathrm{st}$ & 2nd & 9th & 28 th & 19th \\
\hline
\end{tabular}

Figure 8. HOQ2 - linking HE stakeholder requirements and VLE system features (continue) 


\begin{tabular}{|c|c|c|c|c|c|}
\hline \multirow[b]{2}{*}{ VLE system features } & \multirow[b]{2}{*}{ 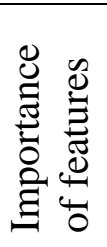 } & \multicolumn{4}{|c|}{ VLE system alternatives } \\
\hline & & A & $\mathrm{B}$ & $\mathrm{C}$ & D \\
\hline 1. System speed & 0.066 & 0.379 & 0.379 & 0.161 & 0.081 \\
\hline 2. Multiple file uploads & 0.021 & 1.000 & $\mathrm{~N} / \mathrm{A}$ & N/A & N/A \\
\hline 3. Digital dropbox & 0.057 & N/A & 1.000 & N/A & N/A \\
\hline 4. Link to SITS & 0.028 & 1.000 & N/A & N/A & N/A \\
\hline 5. Module marks/grades viewing & 0.028 & 0.157 & 0.536 & 0.229 & 0.077 \\
\hline 6. Search engine & 0.071 & 0.567 & 0.272 & 0.081 & 0.081 \\
\hline 7. User interface & 0.011 & 0.267 & 0.563 & 0.108 & 0.062 \\
\hline 8. Ease of navigation & 0.079 & 0.166 & 0.483 & 0.264 & 0.087 \\
\hline 9. Bookmark function & 0.009 & 1.000 & N/A & N/A & N/A \\
\hline 10. Discussion boards/forums & 0.027 & 0.379 & 0.379 & 0.081 & 0.161 \\
\hline 11. Instant messaging & 0.007 & 1.000 & N/A & N/A & N/A \\
\hline 12. Community network & 0.005 & 0.375 & 0.375 & 0.125 & 0.125 \\
\hline 13. Announcement & 0.033 & 0.255 & 0.552 & 0.128 & 0.065 \\
\hline 14. Appointments making & 0.003 & 1.000 & N/A & N/A & N/A \\
\hline 15. Link to library IS portal & 0.044 & 0.484 & 0.301 & 0.143 & 0.072 \\
\hline 16. Link to e-resource databases & 0.036 & 0.359 & 0.359 & 0.082 & 0.200 \\
\hline 17. Link to Webmail & 0.060 & N/A & N/A & N/A & N/A \\
\hline 18. Alerting of new emails & 0.034 & N/A & N/A & N/A & N/A \\
\hline 19. Address book & 0.009 & N/A & 1.000 & N/A & N/A \\
\hline 20. Alerting of new documents & 0.027 & 0.492 & 0.136 & 0.063 & 0.309 \\
\hline 21. Alert through Webmail & 0.025 & 0.333 & 0.333 & 0.167 & 0.167 \\
\hline 22. Manage course menu & 0.012 & 0.233 & 0.542 & 0.140 & 0.085 \\
\hline 23. Course design & 0.012 & 0.233 & 0.542 & 0.140 & 0.085 \\
\hline 24. User-friendly & 0.158 & 0.070 & 0.572 & 0.218 & 0.140 \\
\hline 25. User manual/Tutorial guide & 0.081 & 0.093 & 0.525 & 0.239 & 0.143 \\
\hline 26. Multi-language support & 0.041 & N/A & 1.000 & N/A & N/A \\
\hline 27. Ease of maintenance & 0.002 & 0.301 & 0.484 & 0.143 & 0.072 \\
\hline 28. Continuous product evolution & 0.015 & 0.284 & 0.509 & 0.063 & 0.144 \\
\hline Total score & & 0.259 & 0.434 & 0.125 & 0.089 \\
\hline Ranking & & 2nd & 1 st & $3 \mathrm{rd}$ & 4th \\
\hline
\end{tabular}

Figure 9. HOQ3 - linking VLE system features and VLE system alternatives 
Table I. Applications of AHP, QFD, and their integration in higher education

\begin{tabular}{|c|c|c|}
\hline Approaches & Authors & Applications \\
\hline \multirow[t]{6}{*}{ AHP } & Kwak and Lee (1998) & IT-based project selection \\
\hline & Ozdemir and Gasimov (2004) & Faculty course assignment \\
\hline & Badri and Abdulla (2004) & Faculty performance measurement \\
\hline & Kim et al. (2005) & Course and curriculum design \\
\hline & Lee and Lee (2006) & Subject evaluation and selection \\
\hline & Ho et al. (2007) & Resource allocation \\
\hline \multirow[t]{9}{*}{ QFD } & Jaraiedi and Ritz (1994) & Course and curriculum design \\
\hline & Wiklund and Wiklund (1999) & Course and curriculum design \\
\hline & Hwarng and Teo (2001) & Course and curriculum design \\
\hline & Duffuaa et al. (2003) & Course and curriculum design \\
\hline & Sahney et al. $(2003 ; 2004)$ & Course and curriculum design \\
\hline & Chou (2004) & Course and curriculum design \\
\hline & Aytaç and Deniz (2005) & Course and curriculum design \\
\hline & Denton et al. (2005) & Course and curriculum design \\
\hline & Thakkar et al. (2006) & Course and curriculum design \\
\hline \multirow[t]{2}{*}{ AHP-QFD } & Köksal and Eğitman (1998) & Education requirement selection \\
\hline & Lam and Zhao (1998) & Teaching method selection \\
\hline
\end{tabular}

Table II. AHP pairwise comparison scale

\begin{tabular}{|c|c|c|}
\hline Intensity & Importance & Explanation \\
\hline 1 & Equal & Two activities contribute equally to the object \\
\hline 3 & Moderate & Slightly favors one over another \\
\hline 5 & Strong & Strongly favors one over another \\
\hline 7 & Very strong & Dominance of the demonstrated in practice \\
\hline 9 & Extreme & $\begin{array}{l}\text { Evidence favoring one over another of highest possible } \\
\text { order of affirmation }\end{array}$ \\
\hline $2,4,6,8$ & Intermediate & When compromise is needed \\
\hline $\begin{array}{l}\text { Reciprocals of } \\
\text { the above } \\
\text { numbers }\end{array}$ & & For inverse comparison \\
\hline
\end{tabular}

Table III. List of random index values

\begin{tabular}{|l|l|l|l|l|l|l|l|l|}
\hline$n$ & 2 & 3 & 4 & 5 & 6 & 7 & 8 & 9 \\
\hline$R I(n)$ & 0 & 0.58 & 0.90 & 1.12 & 1.24 & 1.32 & 1.41 & 1.45 \\
\hline
\end{tabular}


Table IV. Descriptions of higher education stakeholder requirements

\begin{tabular}{|c|c|}
\hline Stakeh & Description \\
\hline $\begin{array}{l}\text { 1. Upload/download } \\
\text { documents and course } \\
\text { work efficiently }\end{array}$ & $\begin{array}{l}\text { Documents include module syllabuses and timetables, lecture } \\
\text { notes, tutorial exercises or other assessment materials, past } \\
\text { examination papers, reading lists, and so on. Submission of } \\
\text { assignments belongs to this category }\end{array}$ \\
\hline $\begin{array}{l}\text { 2. Find and locate } \\
\text { documents and course } \\
\text { information easily }\end{array}$ & $\begin{array}{l}\text { After logging in the system successfully, stakeholders may } \\
\text { find a list of modules in their VLE portal, particularly for } \\
\text { students. Within each module, there may be numerous } \\
\text { documents in the middle and end of semester. Therefore, they } \\
\text { would like to find a specific file easily and efficiently }\end{array}$ \\
\hline $\begin{array}{l}\text { 3. Communicate and } \\
\text { collaborate with others }\end{array}$ & $\begin{array}{l}\text { Communication and collaboration include informing students } \\
\text { about updated module information, giving feedbacks to } \\
\text { students on assessments, getting feedback from students about } \\
\text { teaching skill, asking module leaders about lecture materials } \\
\text { and course works, brainstorming and sharing idea in } \\
\text { discussion topics, and many other two-way conversations }\end{array}$ \\
\hline $\begin{array}{l}\text { 4. Search for reference } \\
\text { materials }\end{array}$ & $\begin{array}{l}\text { Reference materials refer to textbooks, reports, journal } \\
\text { articles, conference papers, and newspapers }\end{array}$ \\
\hline $\begin{array}{l}\text { 5. Provide emailing } \\
\text { support }\end{array}$ & $\begin{array}{l}\text { Emailing is a prevalent form of communication for every } \\
\text { stakeholder. Besides sending emails, the stakeholders would } \\
\text { also like to read emails, forward emails, get notice of new } \\
\text { emails, and save and retrieve email addresses }\end{array}$ \\
\hline $\begin{array}{l}\text { re of unread } \\
\text { s/messages }\end{array}$ & $\begin{array}{l}\text { As there may be huge documents and messages in the } \\
\text { modules, the stakeholders would like to identify which items } \\
\text { are newly uploaded or have not read yet }\end{array}$ \\
\hline $\begin{array}{l}\text { 7. Customize displaying } \\
\text { layout and appearance }\end{array}$ & $\begin{array}{l}\text { This is especially important to faculty members because they } \\
\text { have to keep control of module layouts, including which items } \\
\text { should be included in the content areas, the sequence of items, } \\
\text { the style and appearance of items, and so on }\end{array}$ \\
\hline 8. Get started easily & $\begin{array}{l}\text { Most of the stakeholders would like to use the VLE system for } \\
\text { supporting their teaching and learning easily and without any } \\
\text { complicated procedures or programming involved }\end{array}$ \\
\hline $\begin{array}{l}\text { 9. Provide after-sale } \\
\text { services }\end{array}$ & $\begin{array}{l}\text { This requirement was addressed by VLE system } \\
\text { administrators. After-sale services, such as maintenance and } \\
\text { upgrading, are crucial to them }\end{array}$ \\
\hline
\end{tabular}


Table V. Descriptions of VLE system features

\begin{tabular}{l} 
VLE system features \\
\hline 1. System speed \\
2. Multiple file uploads \\
3. Digital dropbox
\end{tabular}

4. Link to SITS

5. Module marks/grades viewing

6. Search engine

7. User interface

8. Ease of navigation

9. Bookmark function

10. Discussion boards/forums

11. Instant messaging

12. Community network

13. Announcement

14. Appointments making

15. Link to library IS portal

16. Link to e-resource databases

17. Link to Webmail

18. Alerting of new emails

19. Address book
Description

Speed of uploading and downloading

Uploading of multiple files simultaneously

It allows stakeholders to exchange files, such as submission of course work and reports to module leaders

SITS is a student record system, which comprises credit accumulation management system, student registration system, and marketing and admissions system

Students can check their marks or grades of assignments, reports, tests, and exams. In addition, distribution of marks, such as highest, average, and lowest marks of modules should be available

For searching files and messages. To facilitate searching, both basic and advanced searches should be available and also the stakeholders can search by file name, date, and other criteria

Appearance and arrangement of contents in the system portal

The stakeholders can locate themselves easily

Similar to web browsers, the stakeholders can add their favorite and frequently visited locations in the VLE system using bookmark function Any stakeholders can post a message to express their thoughts and respond to others on the discussion boards

A form of real-time communication between two or more stakeholders based on typed text

Any stakeholders with similar interests can join and participate in the same local communities so that they can collaborate and study together virtually

It can be regarded as an online notice board.

Administrative staff and faculty members can post the updated information on it

Students can use this function to check the availability of module leaders and make appointments with them

Connect VLE system with library information system portal for searching textbooks and reports directly Connect VLE system with e-resource databases for searching journal articles, conference papers, and newspapers directly

Connect VLE system with institutional Webmail portal for the comprehensive emailing services Similar to Microsoft Outlook Express, VLE system should be able to inform stakeholders of receiving new emails

It allows stakeholders to save and retrieve personal 
20. Alerting of new documents

21. Alert through Webmail

22. Manage course menu

23. Course design

24. User-friendly

25. User manual/Tutorial guide

26. Multi-language support

27. Ease of maintenance

28. Continuous product evolution information of other stakeholders

VLE system should be able to inform stakeholders of new or unread documents and messages

If there is any newly posted messages and documents, the stakeholders should be informed through Webmail

It permits administrative staff and module leaders to determine which items should be displayed in the student portals and their sequence

It permits administrative staff and module leaders to determine the style and properties of the student portals

Easy to use

User manual refers to text-based documents, whereas tutorial guide refers to multimedia-based slideshows. Both of them teach the stakeholders how to use the tools of VLE system

With this feature, stakeholders, particularly international students, are able to set their portal as their mother language

It allows VLE system administrators to solve technical problems easily

It refers to the possibility and speed of introducing new tools and facilities by the VLE system providers 
Table VI. A comparison of the VLE system alternatives with respect to the most important requirement

\begin{tabular}{|c|c|c|c|c|c|}
\hline \multirow[b]{2}{*}{ Attributes of "get started easily" } & \multirow{2}{*}{ 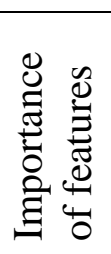 } & \multicolumn{4}{|c|}{ VLE system alternatives } \\
\hline & & A & B & $\mathrm{C}$ & $\mathrm{D}$ \\
\hline 24. User-friendly & 0.158 & 0.070 & 0.572 & 0.218 & 0.140 \\
\hline 25. User manual/Tutorial guide & 0.081 & 0.093 & 0.525 & 0.239 & 0.143 \\
\hline 8. Ease of navigation & 0.079 & 0.166 & 0.483 & 0.264 & 0.087 \\
\hline 26. Multi-language support & 0.041 & N/A & 1.000 & N/A & N/A \\
\hline Total score & & 0.032 & 0.212 & 0.075 & 0.041 \\
\hline Ranking & & 4th & 1 st & 2nd & $3 \mathrm{rd}$ \\
\hline
\end{tabular}

Table VII. A comparison of the VLE system alternatives with respect to the second most important requirement

\begin{tabular}{|c|c|c|c|c|c|}
\hline \multirow[b]{2}{*}{$\begin{array}{l}\text { Attributes of "find and locate } \\
\text { documents and course } \\
\text { information easily" }\end{array}$} & \multirow{2}{*}{ 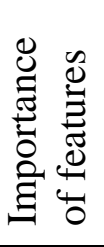 } & \multicolumn{4}{|c|}{ VLE system alternatives } \\
\hline & & A & B & $\mathrm{C}$ & D \\
\hline 8. Ease of navigation & 0.079 & 0.166 & 0.483 & 0.264 & 0.087 \\
\hline 6. Search engine & 0.071 & 0.567 & 0.272 & 0.081 & 0.081 \\
\hline 15. Link to library IS portal & 0.044 & 0.484 & 0.301 & 0.143 & 0.072 \\
\hline 16. Link to e-resource databases & 0.036 & 0.359 & 0.359 & 0.082 & 0.200 \\
\hline 4. Link to SITS & 0.028 & 1.000 & N/A & N/A & N/A \\
\hline 5. Module marks/grades viewing & 0.028 & 0.157 & 0.536 & 0.229 & 0.077 \\
\hline 20. Alerting of new documents & 0.027 & 0.492 & 0.136 & 0.063 & 0.309 \\
\hline 7. User interface & 0.011 & 0.267 & 0.563 & 0.108 & 0.062 \\
\hline 9. Bookmark function & 0.009 & 1.000 & N/A & N/A & N/A \\
\hline Total score & & 0.145 & 0.109 & 0.045 & 0.034 \\
\hline Ranking & & $1 \mathrm{st}$ & $2 \mathrm{nd}$ & $3 \mathrm{rd}$ & 4th \\
\hline
\end{tabular}


Table VIII. A comparison of the VLE system alternatives with respect to the third most important requirement

\begin{tabular}{|c|c|c|c|c|c|}
\hline \multirow[b]{2}{*}{$\begin{array}{l}\text { Attributes of "upload/download } \\
\text { documents and course work } \\
\text { efficiently" }\end{array}$} & \multirow{2}{*}{ 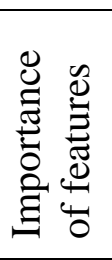 } & \multicolumn{4}{|c|}{ VLE system alternatives } \\
\hline & & A & B & $\mathrm{C}$ & D \\
\hline 1. System speed & 0.066 & 0.379 & 0.379 & 0.161 & 0.081 \\
\hline 3. Digital dropbox & 0.057 & N/A & 1.000 & N/A & N/A \\
\hline 2. Multiple file uploads & 0.021 & 1.000 & N/A & $\mathrm{N} / \mathrm{A}$ & N/A \\
\hline 28. Continuous product evolution & 0.015 & 0.284 & 0.509 & 0.063 & 0.144 \\
\hline Total score & & 0.050 & 0.090 & 0.012 & 0.008 \\
\hline Ranking & & 2nd & $1 \mathrm{st}$ & $3 \mathrm{rd}$ & 4th \\
\hline
\end{tabular}

Table IX. A comparison of the VLE system alternatives with respect to the fourth most important requirement

\begin{tabular}{|c|c|c|c|c|c|}
\hline \multirow[b]{2}{*}{$\begin{array}{l}\text { Attributes of "communicate and } \\
\text { collaborate with others" }\end{array}$} & \multirow{2}{*}{ 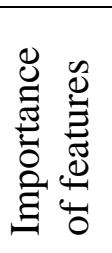 } & \multicolumn{4}{|c|}{ VLE system alternatives } \\
\hline & & A & B & $\mathrm{C}$ & $\mathrm{D}$ \\
\hline 17. Link to Webmail & 0.060 & N/A & N/A & N/A & N/A \\
\hline 3. Digital dropbox & 0.057 & N/A & 1.000 & N/A & N/A \\
\hline 13. Announcement & 0.033 & 0.255 & 0.552 & 0.128 & 0.065 \\
\hline 10. Discussion boards/forums & 0.027 & 0.379 & 0.379 & 0.081 & 0.161 \\
\hline 19. Address book & 0.009 & N/A & 1.000 & N/A & N/A \\
\hline 11. Instant messaging & 0.007 & 1.000 & N/A & N/A & N/A \\
\hline 12. Community network & 0.005 & 0.375 & 0.375 & 0.125 & 0.125 \\
\hline 14. Appointments making & 0.003 & 1.000 & N/A & N/A & $\mathrm{N} / \mathrm{A}$ \\
\hline Total score & & 0.031 & 0.096 & 0.007 & 0.007 \\
\hline Ranking & & 2 nd & $1 \mathrm{st}$ & $3 \mathrm{rd}$ & $3 \mathrm{rd}$ \\
\hline
\end{tabular}


Table X. A comparison of the VLE system alternatives with respect to the fifth most important requirement

\begin{tabular}{|c|c|c|c|c|c|}
\hline \multirow[b]{2}{*}{$\begin{array}{l}\text { Attributes of "provide emailing } \\
\text { support" }\end{array}$} & \multirow{2}{*}{ 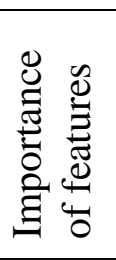 } & \multicolumn{4}{|c|}{ VLE system alternatives } \\
\hline & & A & B & $\mathrm{C}$ & D \\
\hline 17. Link to Webmail & 0.060 & N/A & N/A & $\mathrm{N} / \mathrm{A}$ & N/A \\
\hline 18. Alerting of new emails & 0.034 & N/A & N/A & N/A & N/A \\
\hline 21. Alert through Webmail & 0.025 & 0.333 & 0.333 & 0.167 & 0.167 \\
\hline 19. Address book & 0.009 & N/A & 1.000 & N/A & N/A \\
\hline Total score & & 0.008 & 0.017 & 0.004 & 0.004 \\
\hline Ranking & & 2nd & $1 \mathrm{st}$ & $3 \mathrm{rd}$ & $3 \mathrm{rd}$ \\
\hline
\end{tabular}

Table XI. A comparison of the VLE system alternatives with respect to the sixth most important requirement

\begin{tabular}{|c|c|c|c|c|c|}
\hline \multirow[b]{2}{*}{$\begin{array}{l}\text { Attributes of "search for } \\
\text { reference materials" }\end{array}$} & \multirow{2}{*}{ 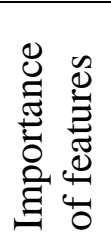 } & \multicolumn{4}{|c|}{ VLE system alternatives } \\
\hline & & A & B & $\mathrm{C}$ & $\mathrm{D}$ \\
\hline 6. Search engine & 0.071 & 0.567 & 0.272 & 0.081 & 0.081 \\
\hline 15. Link to library IS portal & 0.044 & 0.484 & 0.301 & 0.143 & 0.072 \\
\hline 16. Link to e-resource databases & 0.036 & 0.359 & 0.359 & 0.082 & 0.200 \\
\hline 9. Bookmark function & 0.009 & 1.000 & N/A & N/A & $\mathrm{N} / \mathrm{A}$ \\
\hline Total score & & 0.083 & 0.045 & 0.015 & 0.016 \\
\hline Ranking & & $1 \mathrm{st}$ & 2 nd & 4th & $3 \mathrm{rd}$ \\
\hline
\end{tabular}

